\title{
The application of bioactive compounds from the food industry to control mold growth in indoor waterborne coatings
}

\author{
N. Bellotti ${ }^{\mathrm{a}, *, 1}$, L. Salvatore ${ }^{\mathrm{a}}$, C. Deyáa ${ }^{\mathrm{a}, 2,3}$, M.T. Del Panno ${ }^{\mathrm{b}, * *, 3}$, B. del Amo ${ }^{\mathrm{a}, 2}$, R. Romagnoli $^{\mathrm{a}, 2,3}$ \\ a CIDEPINT-Centro de Investigación y Desarrollo en Tecnología de Pinturas (CIC-CONICET), Calle 52 e/121 y 122, B1900AYB La Plata, Argentina \\ ${ }^{\mathrm{b}}$ CINDEFI- Instituto de Biotecnología Aplicada (UNLP-CONICET) Calle 50 y 115 (B1900AJL) La Plata, Buenos Aires, Argentina
}

\section{A R T I C L E I N F O}

\section{Article history:}

Received 12 September 2012

Received in revised form

13 November 2012

Accepted 19 November 2012

Available online 7 December 2012

\section{Keywords:}

Antimicrobial coating

Mold

Biodeterioration

Biocide

\begin{abstract}
A B S T R A C T
Microbial growth in indoor environments creates health problems, especially in people with asthma; approximately $80 \%$ of these patients are allergic to mold. Antimicrobial coatings are formulated to generate surfaces that are easy to clean and may also incorporate active agents, commonly called biocides, which inhibit microbial colonization, subsequent growth and bio-deterioration of the substrates.

Some research lines seek to replace traditional organometallic and organochlorines biocides with environmentally acceptable ones. The aim of this research was, primarily, to explore the possible application of different compounds used in food industry like preservatives to be used as antimicrobial additives for antimicrobial coatings. Four biocides were tested against two different ambient molds isolated from an interior painted wall (Chaetomium globosum and Alternaria alternate). The selected biocides were zinc salicylate, zinc benzoate, calcium benzoate and potassium sorbate. The resulting paints were subjected to biological and physical tests (viscosity, hiding power, humidity absorption and biocides leaching rate). Bioassays revealed that zinc benzoate and zinc salicylate resulted active against both fungi.
\end{abstract}

(c) 2012 Elsevier B.V. All rights reserved.

\section{Introduction}

Mold defacement of paint films is a serious problem which has received increased attention in the last decades. The microbial colonization of painted buildings causes esthetic problems and may lead to coating degradation and spalling. Fungi are heterotrophic organisms that commonly colonize organic building materials like coatings, which can be metabolized by them [1]. Moreover, fungal growing inside buildings can affect people's health by producing quite toxic mycotoxins [2]. Alternaria and Penicillium species spores were shown to cause immediate and delayed-type asthma in individuals already sensitized to these organisms [2]. Spores are released into the environment and their size allow them to penetrate deep into the lower respiratory tract and in certain populations the spores can settle down and cause a wide range of diseases [3]. It is clear that exposure of humans to these fungi must be avoided. In this sense, the employment of antimicrobial

\footnotetext{
* Corresponding author at: CIDEPINT-Centro de Investigación y Desarrollo en Tecnología de Pinturas (CIC-CONICET), Calle 52 e/121 y 122, B1900AYB La Plata, Argentina. Tel.: +54 221 4833794; fax: +54 221 4833794/4271537.

** Corresponding author. Tel.: +54 2214833794 ; fax: +54 2214833794 .

E-mail addresses: pinturashigienicas@cidepint.gov.ar, nataliabe9@hotmail.com (N. Bellotti).

1 CONICET Professional.

2 CONICET Researcher.

3 UNLP Professor.
}

coatings in buildings may contribute to protect and prevent the bio-deterioration of the substrates and create more healthy environments.

There are three principal types of antimicrobial coatings: microbial repelling, biocide releasing and contact killing [4,5]. Microbial repelling surfaces act by inhibiting the initial adhesion of microbial cells, thus preventing biofilm formation [6]. The second type comprises those coatings in which biocides slowly migrate to the paint surface to be released into the environment, killing the microorganisms attached to it $[7,8]$. In the case of the contact-killing mechanism, the antimicrobial agent is attached to the surface in a way that it cannot be released, but it kills microbes coming into direct contact with the surface [9-11].

Antimicrobial coatings need to be effective in controlling microbial growth but there is a great concern about the safety of chemicals used in this type of coatings and building materials because they must be "green" chemicals, especially for in-home uses [12]. These materials are often touted as minimizing chemical emissions as well as for being recyclable, and less toxic. Fungicides commonly used to control the mold growth are not often appropriate for indoor applications and, therefore, more friendly alternative compounds, non-toxic to humans, are desirable for antimicrobial paints [13].

The aim of this research was to assess the efficiency of different compounds, used in food industry as preservatives, to prevent mold growth in indoor waterborne paints [14]. Four biocides were tested against two different ambient molds isolated from an 
interior painted wall. These biocides were zinc salicylate, zinc benzoate, calcium benzoate and potassium sorbate. The molds were identified as Chaetomium globosum and Alternaria alternate [15]. As zinc salicylate and zinc benzoate succeeded in biological tests they were incorporated in a wall paint formulation. The resulting paints were subjected to physical tests such as: viscosity, hiding power, humidity absorption and biocides leaching rate. The bioresistance of paints formulated with these biocides was assessed by the accelerated four-week agar plate assay [16].

\section{Materials and methods}

\subsection{Antimicrobial activity}

Biocides inhibitory activity was evaluated by an in vitro fungal growth inhibition assay which takes into account that mold growth can be assessed by measuring colony diameters on agar plates over time $[14,17]$.

The fungal isolates used to carry on this test ( $C$. globosum and Alternaria alternata) were obtained, previously, from contaminated indoor coatings [15]. The spore suspension was prepared from subcultures of each fungal isolate growth in solid culture medium (CM-agar) during 25-30 days at $25 \pm 2{ }^{\circ} \mathrm{C}$. The CM-agar was composed of glucose, $10 \mathrm{~g}$; peptone, $5 \mathrm{~g} ; \mathrm{KH}_{2} \mathrm{PO}_{4}, 1 \mathrm{~g}$; $\mathrm{MgSO}_{4} \cdot 7 \mathrm{H}_{2} \mathrm{O}$, $0.5 \mathrm{~g}$ and agar, $15 \mathrm{~g}$, dissolved in $1000 \mathrm{~mL}$ of distilled water (DW). Spores were removed from the well grown cultures and deposited in a flask with $5 \mathrm{~mL}$ of physiological solution containing $\mathrm{NaCl} 0.85 \%$ $(\mathrm{w} / \mathrm{v})$ and Tween $200.005 \%(\mathrm{w} / \mathrm{v})$. The concentration of spores was adjusted to $0.3-0.5 \times 10^{6}$ spores/mL employing a Neubauer chamber.

The CM-agar with $0.03 \%(\mathrm{w} / \mathrm{v}$ ) of the corresponding biocide was poured into Petri dishes which were inoculated with $10^{2}$ spores of each fungal suspension in a single point located at the center. The same procedure was carried out with control CM-agar without biocides. The CM-agar plates were incubated at $25^{\circ} \mathrm{C}$ and periodically the colony diameter was recorded.

\subsection{Paints physical tests}

A commercial latex paint (Borgolatex ${ }^{\circledR}$ ) was employed as blank. Each biocide, $0.6 \%(\mathrm{w} / \mathrm{w})$, was added to this paint in a high speed disperser and stirred in order to achieve an acceptable dispersion degree. The biocide concentration was adjusted taking into account the viscosity modification of the original paint (high viscosity makes difficult paint application) and ensuring a minimum amount of biocide enough to act against mold.

Paints characterization was accomplished through different tests. The viscosity of the resulting paints was determined with a Stormer viscometer [18]. The hiding power and the washability degree were evaluated according to the IRAM (Instituto Argentino de Normalización y Certificación) 1070 standard. The loss of weight of the paints was determined at different temperatures in order to know the amount of solvent, resin, organic additives and solid pigments. A certain amount of paint was placed in a capsule previously heated at $1000^{\circ} \mathrm{C}$ and cooled down to $25^{\circ} \mathrm{C}$ in a desicator, weighted in an analytical balance. Then, the capsule was heated at $100^{\circ} \mathrm{C}$ until constant weight, in order to know the amount of solvent present in the paint formulation. After weighted, the capsule was placed in a stove at $600^{\circ} \mathrm{C}$, until constant weight, to know the amount of resin and organic additives. The procedure was repeated at $1000^{\circ} \mathrm{C}$ to determine the amount of pigments present in the paints, which were weighted as the corresponding oxides.

Two coats of paints were applied on sandblasted acrylic panels and allowed to dry $24 \mathrm{~h}$ between each application. Different essays were carried out on these painted panels. The humidity absorption tests were carried out in a tight humidity chamber with an $\mathrm{NH}_{4} \mathrm{Cl}$ saturated solution to achieve a relative constant humidity $(\mathrm{RH})$ of $79.5 \%$ at $20^{\circ} \mathrm{C}$. Acrylic panels $(10 \mathrm{~cm} \times 2 \mathrm{~cm})$ were weighted before placing them in the chamber and after 3,24 and $48 \mathrm{~h}$ and after 4 days. Then, the panels were removed and placed in a similar chamber with $\mathrm{H}_{2} \mathrm{SO}_{4}$ solution $\left(\delta=1.6 \mathrm{~g} \mathrm{~cm}^{-3}\right), 8.5 \% \mathrm{RH}$ at $20^{\circ} \mathrm{C}$, for 2 days, and weighted again in order to study the recovery of the dried condition. Finally, the panels were brought back to the initial conditions $\left(79.5 \% \mathrm{RH}\right.$ at $20^{\circ} \mathrm{C}$ ) for $24 \mathrm{~h}$ to determine if they were able to recover the same level of water absorption.

The leaching rate of biocides was determined by immersing painted acrylic panels $(8 \mathrm{~cm} \times 8 \mathrm{~cm})$ in $230 \mathrm{ml}$ of DW. The zinc leached was determined on a $1.00 \mathrm{ml}$ aliquot at different times by atomic absorption. The $\mathrm{pH}$ changes were monitored, because the leaching and further hydrolysis of benzoate or salicylate anion generate an alkaline medium. The original level of the liquid was restored periodically by adding fresh DW. Leached benzoate and salicylate were determined by UV spectrophotometry. Salicylate was determined at $297 \mathrm{~nm}$ and benzoate at $275 \mathrm{~nm}$ in an acidic methanol solution [19]. Sodium salicylate and sodium benzoate solutions were used as standards.

Fourier transformed infra-red spectroscopy (FTIR) was done on dried paints in order to chemically characterize them.

\subsection{Coatings bio-resistance test}

Paints were applied on $7.5 \mathrm{~cm} \times 2.5 \mathrm{~cm}$ glasses previously cleaned with DW and dried at $25^{\circ} \mathrm{C}$. Two coats of paints were applied and allowed to stand $24 \mathrm{~h}$ between each application. Samples were cured for two weeks in laboratory atmosphere $\left(20 \pm 2{ }^{\circ} \mathrm{C}, 75 \% \mathrm{RH}\right)$ before testing and, then, cut into square pieces $(\sim 2.5 \mathrm{~cm} \times 2.5 \mathrm{~cm})$.

The painted glasses were irradiated with a germicide UV-lamp from Philips (20 W) for $40 \mathrm{~min}$, each side, to avoid contamination. Afterward, the glasses were place in a Petri dish with solid minimum mineral medium (MMM-agar). Three glasses were placed in each plate, one coated with the control paint, and the other two with the paints containing the biocides.

The MMM-agar was prepared dissolving $5 \mathrm{~g} \mathrm{NaCl}, 1 \mathrm{~g} \mathrm{HK}_{2} \mathrm{PO}_{4}$, $1 \mathrm{~g}\left(\mathrm{NH}_{4}\right) \mathrm{H}_{2} \mathrm{PO}_{4}, 1 \mathrm{~g}\left(\mathrm{NH}_{4}\right)_{2} \mathrm{SO}_{4}, 0.2 \mathrm{~g} \mathrm{MgSO}_{4}, 3 \mathrm{~g} \mathrm{KNO}_{3}$ and $15 \mathrm{~g}$ of agar in DW $(1000 \mathrm{ml})$. This medium was selected for their poor growing conditions, just to force the mold to grow on the painted panel, employing the paint as the carbon source.

Molds inoculums were prepared by growing each isolate (C. globosum and $A$. alternata) in CM-agar for 25-30 days in the same condition than the other bioassay. A $50 \mu \mathrm{l}$ aliquot of the spore suspension was placed on the painted glasses, distributed homogenously all over the surface, incubated at $25^{\circ} \mathrm{C}$ and observed every week with a magnifying glass (MG).

The rate of fungal growth on paint films was assessed using the reference scale of the ASTM D5590-00 standard specification. Therefore observed growth on specimens corresponding to: none, trace of growth $(<10 \%)$, light growth $(10-30 \%)$, moderate growth (30-60\%), heavy growth (60-100\%) has been rating as $0,1,2,3$, and 4.

\section{Results and discussion}

\subsection{Antimicrobial activity}

Biocides inhibitive performance was assessed by measuring the diameters of the fungal growth on CM-agar, against time (Figs. 1 and 2). Zinc salicylate and zinc benzoate proved to be the most effective biocides, photographs taken with both isolates at their first week of incubation are shown in Fig. 3; as a consequence, 


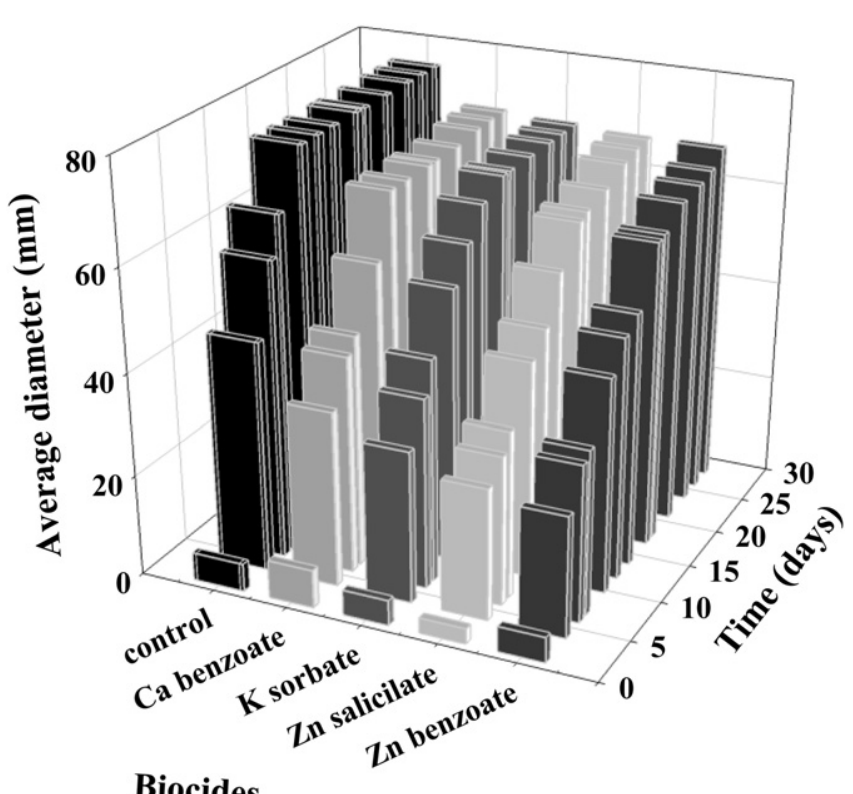

\section{Biocides}

Fig. 1. C. globosum, average growth diameter with different biocides.

they were incorporated into the paints. C. globosum was more affected by these biocides showing a tendency to decrease the growth rate in approximately a half at the end of the first week.

\subsection{Physical tests}

The viscosity of the paints increased after the incorporation of the biocides (Zinc salicylate and Zinc benzoate) from 86 (control)

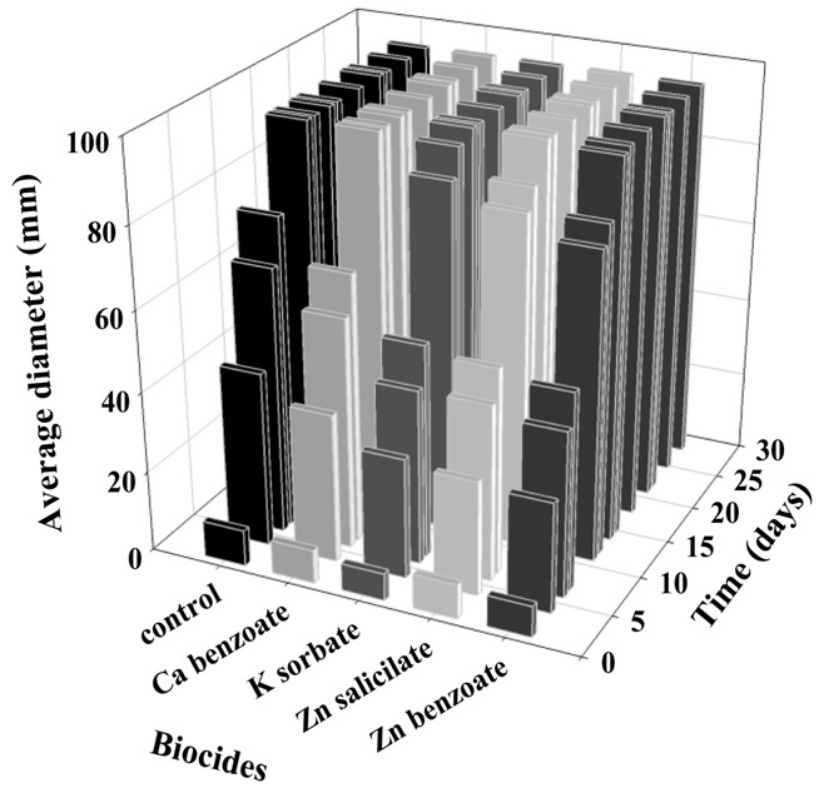

Fig. 2. A. alternate, average growth diameter with different biocides.

to 100 and $121 \mu$ krebs respectively; however, neither the hiding power nor the washability was modified. The only exception was the paint with zinc benzoate whose washability diminished from 10 cycles (control and paint with zinc salicylate) to 7 cycles.

The paint chemical analysis by indirect gravimetry reveled that the amount of solvent was $39.2 \%$ and the amount of resin $25.2 \%$, being the rest inorganic solids.

The FTIR spectra of the coatings showed the bands due to $\mathrm{CaCO}_{3}$ $\left(2609,1798,1460 \mathrm{~cm}^{-1}\right)$ and talc $\left(1022 \mathrm{~cm}^{-1}\right)$ as well as the typical

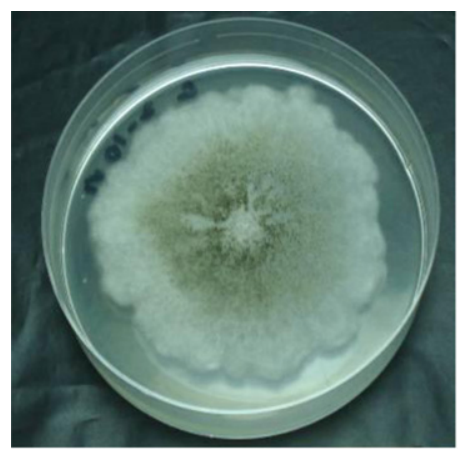

a) Control

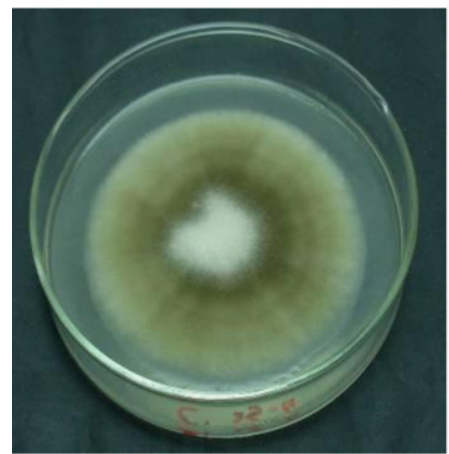

d) Control

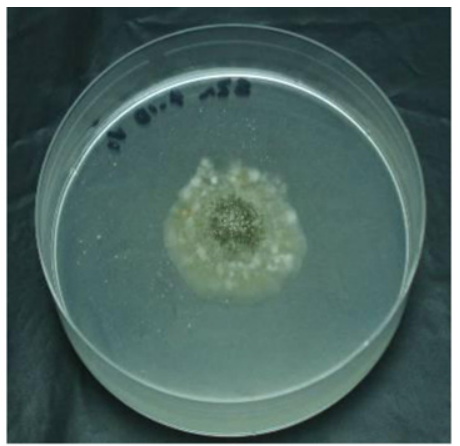

b) Zn salicylate

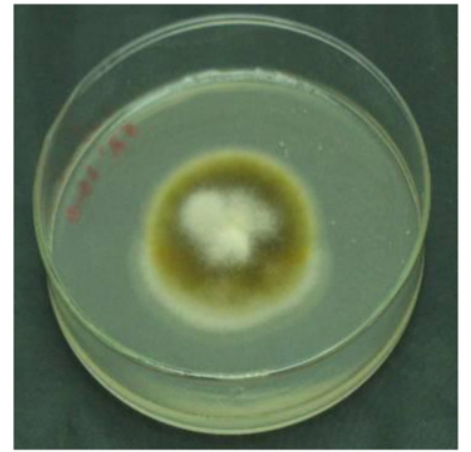

e) Zn salicylate

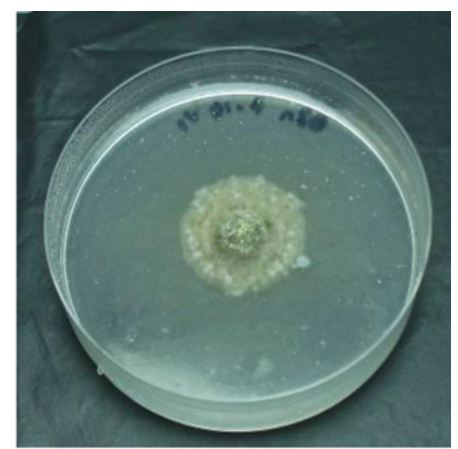

c) Zn benzoate

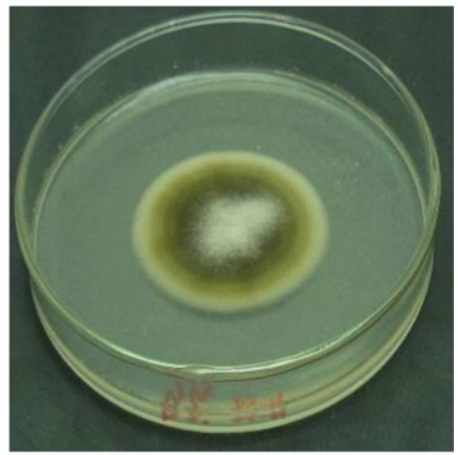

f) $\mathrm{Zn}$ benzoate

Fig. 3. C. globosum (a)-(c) and A. alternata (d)-(f) growth on CM-agar plates after a week at $25^{\circ} \mathrm{C}$ with and without biocides. 
Table 1

Humidity absorption tests as \% by weight of the panel mass.

\begin{tabular}{|c|c|c|c|c|c|c|c|}
\hline \multirow{3}{*}{ Paints } & \multicolumn{7}{|c|}{ Time (h) } \\
\hline & \multicolumn{4}{|c|}{$79.5 \% \mathrm{RH}$} & \multicolumn{2}{|c|}{$8.5 \% \mathrm{RH}$} & \multirow{2}{*}{$\begin{array}{l}79.5 \% \mathrm{RH} \\
24\end{array}$} \\
\hline & 3 & 24 & 48 & 96 & 3 & 24 & \\
\hline Control & 0.4 & 1.3 & 1.5 & 2.6 & -1.0 & -2.6 & 1.2 \\
\hline Zn salicylate & 0.4 & 1.2 & 1.4 & 2.3 & -1.0 & -2.3 & 1.1 \\
\hline Zn benzoate & 0.3 & 0.9 & 1.0 & 1.8 & -0.7 & -1.8 & 0.9 \\
\hline
\end{tabular}

Table 2

Biocides leaching rate tests.

\begin{tabular}{|c|c|c|c|c|c|c|c|c|c|c|}
\hline \multirow{3}{*}{ Paints } & \multicolumn{10}{|c|}{ Time (h) } \\
\hline & \multicolumn{5}{|l|}{$\mathrm{pH}$} & \multicolumn{5}{|c|}{ Conductivity $(\mu S)$} \\
\hline & 1 & 3 & 24 & 48 & 1100 & 1 & 3 & 24 & 48 & 1100 \\
\hline Control & 7.4 & 8.6 & 8.6 & 8.3 & 7.2 & 17.0 & 32.0 & 52.0 & 67.2 & 110.5 \\
\hline Zn salicylate & 5.6 & 8.3 & 8.7 & 8.5 & 7.7 & 9.9 & 38.3 & 58.6 & 78.2 & 117.6 \\
\hline Zn benzoate & 6.2 & 8.2 & 8.6 & 8.5 & 7.8 & 22.7 & 35.4 & 75.2 & 86.5 & 156.8 \\
\hline
\end{tabular}

Table 3

Fungal growth rating from bio-resistance tests.

\begin{tabular}{|c|c|c|c|c|c|c|c|c|}
\hline \multirow{2}{*}{ Paints } & \multicolumn{8}{|c|}{ Growth rating for week } \\
\hline & \multicolumn{4}{|c|}{ C. globosum } & \multicolumn{4}{|c|}{ A. alternata } \\
\hline Control & 3 & 3 & 3 & $\overline{4}$ & 4 & 4 & 4 & 4 \\
\hline Zn salicylate & 1 & 1 & 1 & 1 & 3 & 4 & 4 & 4 \\
\hline Zn benzoate & 2 & 2 & 3 & 3 & 3 & 3 & 3 & 3 \\
\hline
\end{tabular}

one for the acrylic resin at $1720 \mathrm{~cm}^{-1}$ (Fig. 4). $\mathrm{CaCO}_{3}$ and talc are common inert pigments used in latex paints. The bands due to the biocides did not appear, probably due to their low amount in the paint.

Humidity absorption tests showed that all coatings absorbed similar amounts of water after $96 \mathrm{~h}$. This amount of water was fully released after $24 \mathrm{~h}$ in a low-humidity environment and the absorption capacity was recovered (Table 1 ). These tests would be indicating that the coatings do not retain water by varying the conditions from high to low humidity environment. It must be concluded that this property was not affected by the addition of biocide.

Leach rate results of the leaching rate tests are displayed in Table 2. At the beginning of the test, $\mathrm{pH}$ of the leachate of the

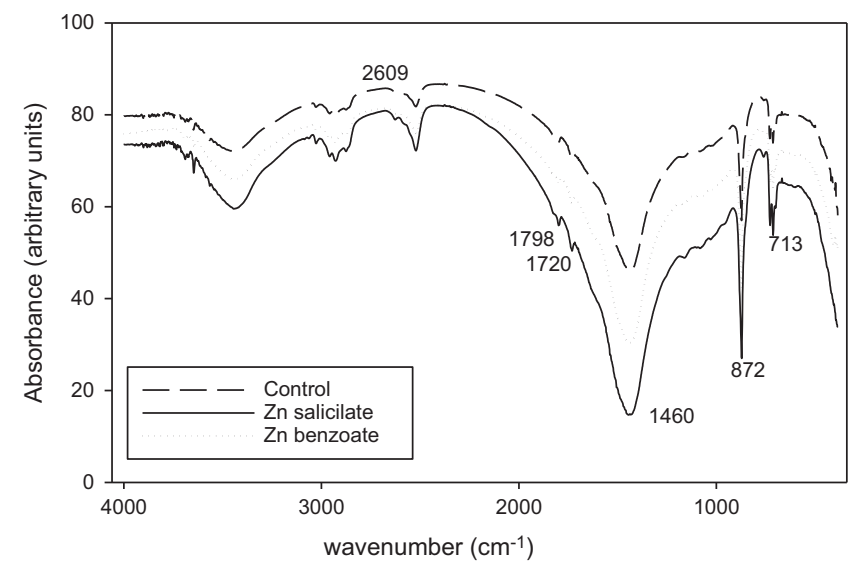

Fig. 4. Coatings FTIR spectra. coatings with biocides was closer to the values corresponding to aerated DW (5.7) while the $\mathrm{pH}$ of the control was found to be 7.4. However, as time elapsed, the $\mathrm{pH}$ of every solution increased and, after $1100 \mathrm{~h}$ of immersion, the $\mathrm{pH}$ of both "leachates" was close to 7.5. This fact could be attributed to the leaching of alkaline species from the coating and to the hydrolysis of salicylate and benzoate anions. The conductivity of the supernatant increased, from $\sim 10.0$ to $\sim 130 \mu \mathrm{S}$ and was a little higher for the paints containing the biocides, thus indicating the solubilization of these. The amount of zinc cation in the supernatant could not be measured because of its very low concentration, just under the detection limit of the method $(0.4 \mathrm{ppm})$. The total amount of salicylate and benzoate leached was $51 \mathrm{ppm}$ and $46 \mathrm{ppm}$ respectively. When water in contact with the coatings was periodically changed, salicylate and benzoate anions could not be measured due to their low concentration.

\subsection{Coatings bio-resistance tests}

The evaluation of the coating samples exposed to fungal isolates in the MMM-agar plates during four week are shown in Table 3. The coating containing $\mathrm{Zn}$ salicylate appeared to be more active against $C$. globosum isolate but just the opposite occurred with the paint containing $\mathrm{Zn}$ benzoate, which was more effective on $A$. alternate.

The growth of $C$. globosum was more affected by the biocides than the other isolate; so it was selected to be observed by scanning electron microscopy (SEM) at low vacuum. The released material by the mycelium of the fungi facilitates the growth of other microorganisms like bacteria which in turn, contributes to film deterioration (Fig. 5b). Biocides also induced changes in the morphological aspects of its spores, Fig. $5 \mathrm{c}$ and $\mathrm{d}$. 
(a)

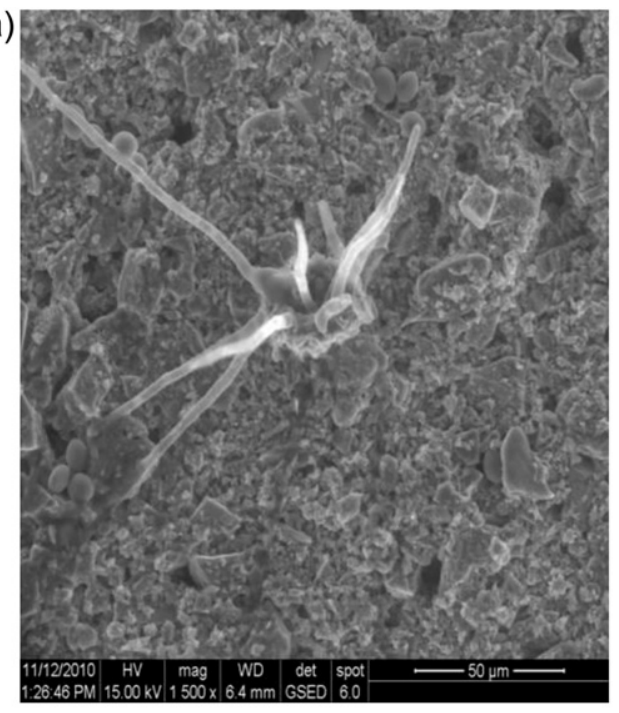

(c)

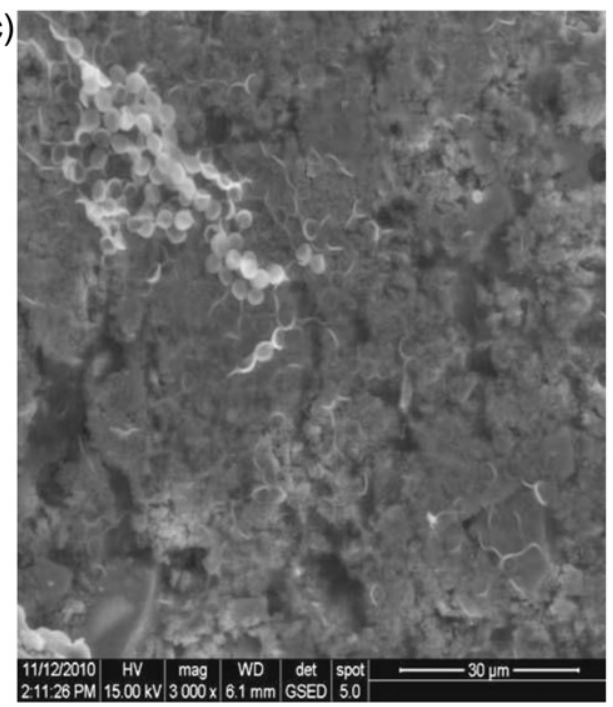

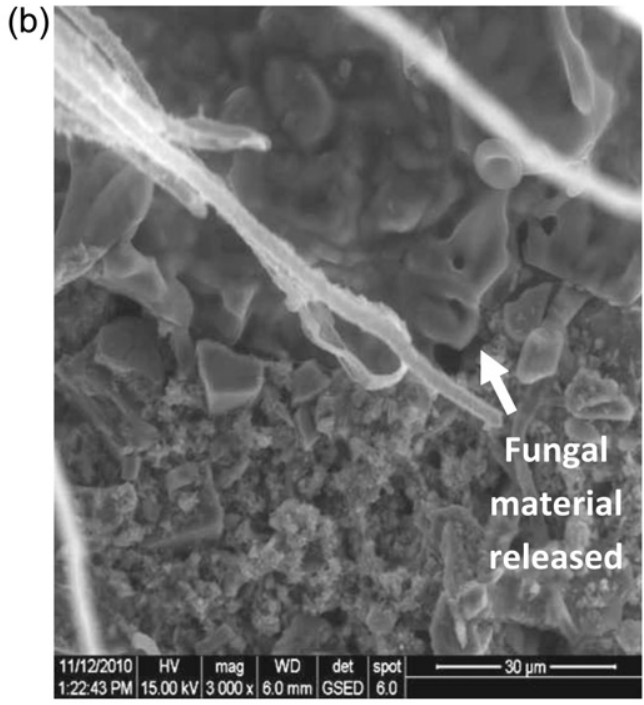

(d)

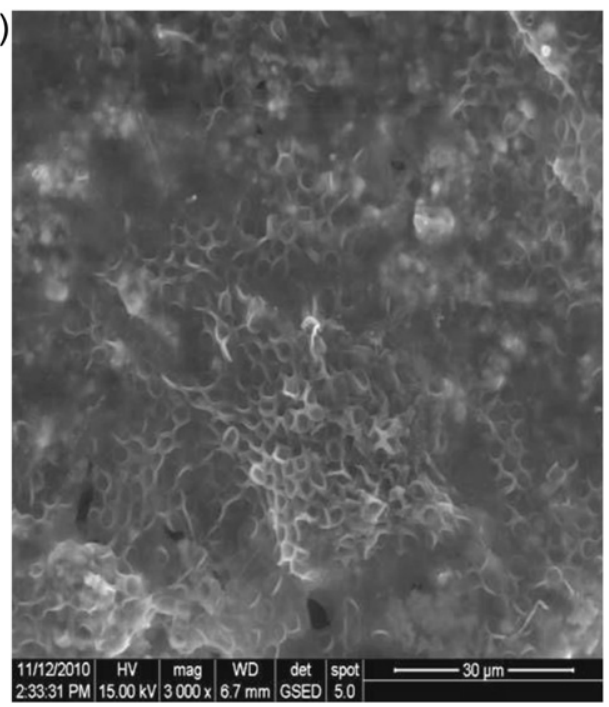

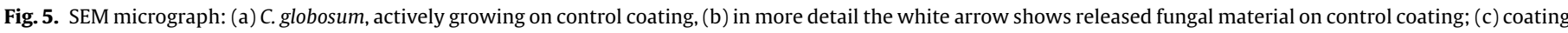
with $\mathrm{Zn}$ salicylate and (d) coating with $\mathrm{Zn}$ benzoate.

\section{Conclusions}

The addition of the biocides does not significantly modify the physical properties of the paint. Zinc benzoate and zinc salicylate resulted active against $C$. globosum and A. alternate, reducing the fungal growth in CM-agar and the coatings. The coating with Zinc benzoate resulted more efficient in inhibiting the growth of $A$. alternate than the coating formulated with zinc salicylate. Biocides leached from the tested coatings in small amounts over time.

\section{Acknowledgments}

The authors wish to thank to Consejo Nacional de Investigaciones Científicas y Técnicas (CONICET), Comisión de Investigaciones Científicas de la Provincia de Buenos Aires (CICPBA), Agencia Nacional de Promoción Científica y Tecnológica (ANPCyT) and the Universidad Nacional de La Plata (UNLP) for the support to do this research. They also thank to Gastón Guzmán for the analytical determinations.

\section{References}

[1] D. Li, C.S. Yang, Adv. Appl. Microbiol. 55 (2004) 31-97.
[2] J.D. Cooley, W.C. Wong, C.A. Jumper, D.C. Straus, Adv. Appl. Microbiol. 55 (2004) 3-30.

[3] D. Sullivan, G. Moran, D. Coleman, in: K. Kavanagh (Ed.), Fungi, Biology and Applications, John Wiley \& Sons, England, 2005, pp. 171-217.

[4] K. Johns, Surf. Coat. Int. B: Coat. Trans. 86 (2003) 101-110.

[5] J.C. Tiller, Eur. Coat. 2 (2007) 21-23.

[6] I.P. Parkin, R.G. Palgrave, J. Mater. Chem. 15 (2005) 1689-1695.

[7] M. Edge, N.S. Allen, D. Turner, J. Robinson, K. Seal, Prog. Org. Coat. 43 (2001) $10-17$.

[8] U. Konwar, N. Karak, M. Mandal, Prog. Org. Coat. 68 (2010) 265-273.

[9] E. Kenawy, F.I. Abdel-Haya, A. El-Raheem, R. El-Shanshouryb, M.H. El-Newehy, J. Control. Release 50 (1998) 145-152.

[10] Z. Cao, Y. Sun, ACS Appl. Mater. Interfaces 2 (2009) 494-504.

[11] L. Hochmannova, J. Vytrasova, Prog. Org. Coat. 67 (2010) 1-5.

[12] C.P. Hoang, K.A. Kinney, R.L. Corsi, P.J. Szaniszlo, Int. Biodeterior. Biodegrad. 64 (2010) 104-113.

[13] A.S. Clare, J. Mar. Biotechnol. 6 (1998) 3-6.

[14] M.E. Guynot, A.J. Ramos, V. Sanchis, S. Marín, Int. J. Food Microbiol. 101 (2005) 61-168.

[15] L. Salvatore, R. Romagnoli, B. del Amo, N. Bellotti, M.T. Del Panno, 3er. Encuentro de Jóvenes Investigadores, 2010, SAM T No. 11-12.

[16] ASTM D5590-00, Standard Test Method for Determining the Resistance of Pain films and Related Coatings to Fungal Defacement by Accelerated Four-Week Agar Plate Assay.

[17] S. Marín, D. Cuevas, A.J. Ramos, V. Sanchos, Int. J. Food Microbiol. 121 (2008) 139-149.

[18] ASTM D562-10 Standard Test Method for Consistency of Paints Measuring Krebs Unit (KU) Viscosity Using a Stormer-Type Viscometer.

[19] F.D. Snell, C.T. Snell, Colorimetric Methods of Analysis, D. Van Nostrand Company, New York, 1941. 